\title{
The Development of BIM-based Augmented Reality System for Fire Safety Equipment Inspection
}

\author{
Yi-Jao, Chen ${ }^{\mathrm{a}, *}$, Yong-Shan, Lai ${ }^{\mathrm{a}}$, Chung-Wei, Feng ${ }^{\mathrm{b}}$ \\ ${ }^{a}$ National University of Kaohsiung, \#700 University Road, Kaohsiung, Taiwan \\ ${ }^{b}$ National Cheng-Kung university, \#1, University Road, Tainan, Taiwan
}

\begin{abstract}
The purpose of fire safety equipment inspection and maintenance is to enable the equipment to start correctly and perform its expected function when fire protection is required to achieve disaster reduction. In the current fire protection maintenance inspection operation stage, the content and methods of inspection stipulated by the regulations are to be followed. Therefore, the relevant file drawings must be consulted before the inspection and maintenance operations are performed. However, because the documents and files are still in paper form, it is difficult to determine and read the information on the inspection and maintenance operations. In addition, it is time-consuming as well as strenuous. To solve the above problems and to help inspectors obtain the information they need as efficiently as possible, this study uses the building information model (BIM) to build the components of fire safety equipment while simultaneously inputting data related to the components' life cycle into the Revit 3D model using the COBie Toolkit. The data are further organized into a cloud database to enable augmented reality processes such as visual simulation and the use of mobile devices in future inspections. This eliminates the limitations of paper-based documents. In terms of system development and case verification, this study used augmented reality technology to present visual simulation of the equipment. The selected case studies demonstrate that BIM ensures the integrity, accessibility, and efficacy of data, while the augmented reality technology combines data with physical objects to provide information immediately in a visible and convenient manner. The developed model therefore is an effective tool that efficiently meets the requirements of fire safety equipment maintenance inspections.
\end{abstract}

(C) 2018 The Authors. Published by Diamond Congress Ltd., Budapest University of Technology and Economics Peer-review under responsibility of the scientific committee of the Creative Construction Conference 2018.

Keywords: augmenter reality $(A R)$; building information model $(B I M)$; construction-operations building information exchange (COBie) ; information exchange; fire safety equipment testing.

\section{Introduction}

In a project life cycle, the importance of a project in the operation and maintenance phase is not less than that in the planning and construction phase. Traditionally, there are still numerous paper documents recording the maintenance and management operations of a project. However, with the increasingly large and complex building scale, handover drawings and descriptions after the completion of a project cannot meet the needs of the owners for facility maintenance. The vast paper documents are not only to be preserved but must also effectively provide the required information for the maintainer [1], the absence of which leads to problems such as a tedious operation pattern, reduction in the maintenance efficiency, and increase in the maintenance cost [2].

It can be learned from relevant research studies that the causes of the difficulties in facility maintenance management operations originate from the incomplete and inconsistent information on buildings. For overcoming such a deficiency, prior research works proposed some advance practices. Tserng et al. designed a set of establishing processes for an electromechanical facility component database to organize the establishment and installation of electromechanical 
facility components (such as weight, position, and length) [3]. Zhang et al. suggested an optimization of a building facility maintenance management system in which the structures of the buildings were initially divided into different levels and then the maintenance equipment project was input. The time was set as finite and infinite in the linear programming, and the life cycle of the facility maintenance management optimization system was applied [4]. Although a facility maintenance management system can improve the work efficiency, the complexity of the system components in the system is still an important factor determining whether the data attributes can meet the information requirements of the operations.

In recent years, with the rapid development in the building information modeling (BIM) model, BIM has been used as the core of the project life cycle information integration. Its application and support in the design and construction phase have been effective. The attribute information of the components and visualized features [6] in a BIM model are able to present attribute data on the geometric appearance, space concept, as well as general objects such as building components of the facilities and windows. For example, Lin \& Su utilized a two-dimensional (2D) barcode system to record various components and codes and combined BIM to promote the advantage of a three-dimensional (3D) system. This allowed the participants of the project to effectively develop a comprehensive understanding of the entire project information in the maintenance phase. Furthermore, the authors established a BIM-based facility maintenance management (BIMFMM) mode system based on BIM, wherein the maintainers used interviews and BIM to inspect the relevant facility maintenance records; thus, yielding a higher efficiency of the FMM [7]. However, in most cases, the application of BIM to the facility operation and maintenance phase was stopped after a preliminary study [8], and it has not yet been practical for actual FMM. In is because apart from the dependence of most of the current BIM model construction platforms on the design or construction requirements, the BIM data attribute framework still cannot include the information and content required by facility operation and maintenance. Additionally, to improve the application benefit of BIM, relevant research studies have indicated that the combination with argument reality (AR) technology would contribute to the information usage efficiency of a BIM model [9,10]. However, Chau et al. stated in their research [11] that the combined application of the AR technology and a BIM model still had a limited utilization benefit, where the important key was the necessity of establishing a feasible information collection mechanism to conform to the information requirements of the users.

To improve the aforementioned shortcomings, the method used in this study integrating the related facility maintenance pattern, information exchange standard, and relevant specification information by considering a BIM model as the core may be feasible and applicable for the FMM requirements. However, different types of information attributes, information usage, and information presentation mode still have to be considered so that the FMM application pattern based on the BIM model can be effectively implemented. Therefore, the research range is set as the facility maintenance phase of the life cycle. The analysis of the information needs of the facility maintenance application, describable multifaceted building standard element attribute structure, facility maintenance pattern, and BIMFMM application are discussed and studied in this research. We expect to achieve integrality, mobility, and validity of information usage as well as immediacy, visibility, and convenience based on the information provided by the integrated application of the BIM model and AR technology. Moreover, the research aims to further enlarge and expand the application of FMM under the developing framework of BIM.

\section{Information analysis of facility maintenance management inspection maintenance}

For a fire protection equipment, this study first establishes the delivery specifications conforming to the fire safety equipment inspection maintenance, then identifies the information delivery relation between the operations as a whole based on the information delivery framework proposed by NIST [12] and the overall process of the IDEF0 analysis information delivery, and next, forms the contents in accordance with the demands of the operation process.

\subsection{Analysis of information content of fire safety equipment}

The requirements of operation inspection maintenance of fire safety equipment can be classified as: (1) requirements ensuring the inspection maintenance operation when the receiving switchboard gives the light signal and (2) requirements for the routine inspection operation of the maintenance plan and fire protection regulations. In consideration of the actual operating phase, the fire protection equipment components can be categorized into: visible fire protection equipment (components visible to the naked eye) and non-visible building construction or fire protection equipment in decoration. Thus, the following two inspection maintenance information presentation patterns are proposed: 
(1) Information presentation of visible fire protection equipment inspection maintenance

Visible fire protection equipment inspection implies that the fire protection equipment visible to the naked eye can be inspected by it by performing the regulatory inspection of the components and maintenance plan. Alternatively, when the fire protection switchboard raises an abnormal signal, the inspection personnel can enter the corresponding space where the signal originated to conduct the inspection operation with the naked eye.

Therefore, the preliminary concept for visible information is formed as shown in Fig. 1, which is regionally divided based on the fire alarm layout plan and integrated with the fire protection equipment inspection maintenance to acquire the inspection maintenance information content and build the cloud database in the information delivery phase. This allows presentation of the relevant maintenance information of abnormality of the fire protection equipment when the inspection personnel scans the mark tracking code in real time with mobile devices (e.g., smart phone and tablet computer) after noticing the abnormal light signal generated by the receiving switchboard. A routine maintenance plan and regulatory inspection can also present the inspection information content using this pattern.

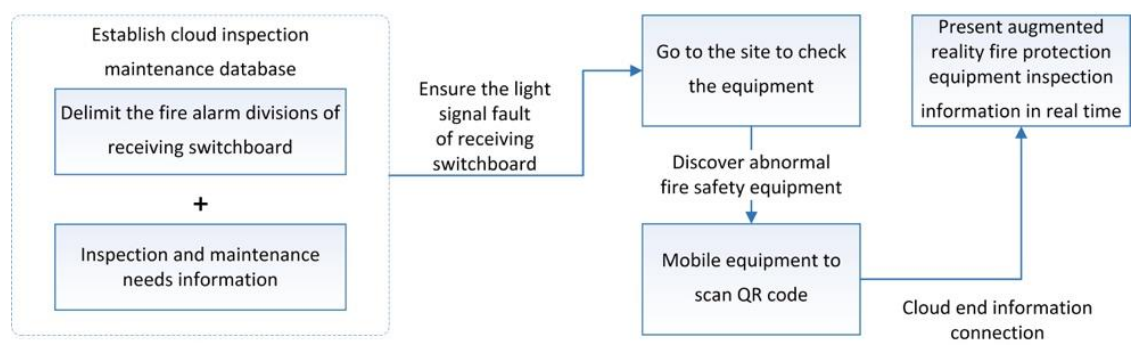

Fig. 1. Visible fire protection device inspection maintenance framework.

(2) Information presentation of non-visible fire protection equipment inspection maintenance

A non-visible fire protection equipment, which is built at the time of project planning and design, is planned for building structures or interior decoration. Thus, it increases the difficulty in the maintenance in the post-operational maintenance phase. However, the traditional maintenance operation mode in contrast with 2D architectural drawings, significantly increases the inconvenience of the maintenance. Therefore, this study will generate effective fire protection equipment delivery content via a BIM model and further establish a 3D cloud fire protection equipment component database by transforming the BIM file into a 3D model, which allows using mobile devices to scan the mark tracking code to obtain hidden fire protection information (as illustrated in Fig. 2).

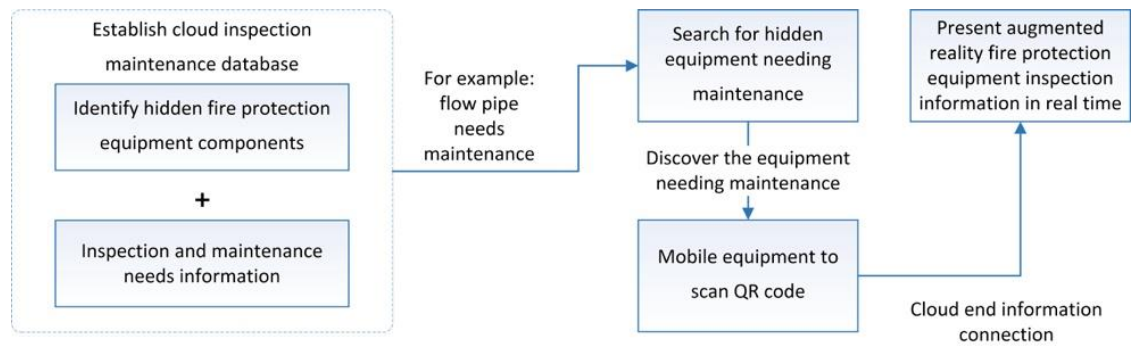

Fig. 2. Non-visible fire protection equipment inspection maintenance framework.

\subsection{Establishment of inspection information application framework}

A follow-up study will analyze the inspection operation process via IDEF0, as shown in Fig. 3, where B1 is the operation needed to be conducted when the fire safety equipment inspection is in process and its operation content includes site exploration and inspection according to a routine inspection or an abnormal signal from the receiving switchboard. After checking the equipment components of the project, the B2 diagnosis operation is followed to conduct diagnostic testing according to a regulatory testing. The equipment condition is examined sequentially based on the fire safety equipment examination table, and if no abnormal condition of the equipment is found, the fire protection equipment engineer selects the "equipment normal" entry on the examination table directly. However, if the equipment is abnormal, the fire protection equipment engineer proposes a fire safety equipment inspection report to conduct the B3 disposal operation, which is to send a maintenance unit to conduct the equipment maintenance 
according to the fire safety equipment inspection report and equipment operation handbook. If the abnormal condition can be solved immediately, the fire protection equipment engineer selects the "equipment normal" entry on the examination table, and in case the abnormal condition cannot be debugged instantly, the B4 operation is followed. In this operation, the fire protection equipment engineer proposes a fire safety equipment improvement plan to allow the management owner to implement it according to declared requirements and original completion document. Finally, the inspection operation is performed after the completion of the plan in B5, in which the manufacturer performs the repair according to the equipment design drawing, and the fire protection equipment engineer conducts the detection completion and inspection declaration after the completion of the repair.

Based on the above analysis results, this study will subdivide each operation into sub-operations on the basis of the fire safety equipment inspection analysis process, define the corresponding relationship between the sub-operations and participants, and classify the three types of information required by the COBie organization information framework to enable COBie Toolkit to provide more accurate information content. In this study, a COBie delivery handbook will be written after the development of the information requirements.

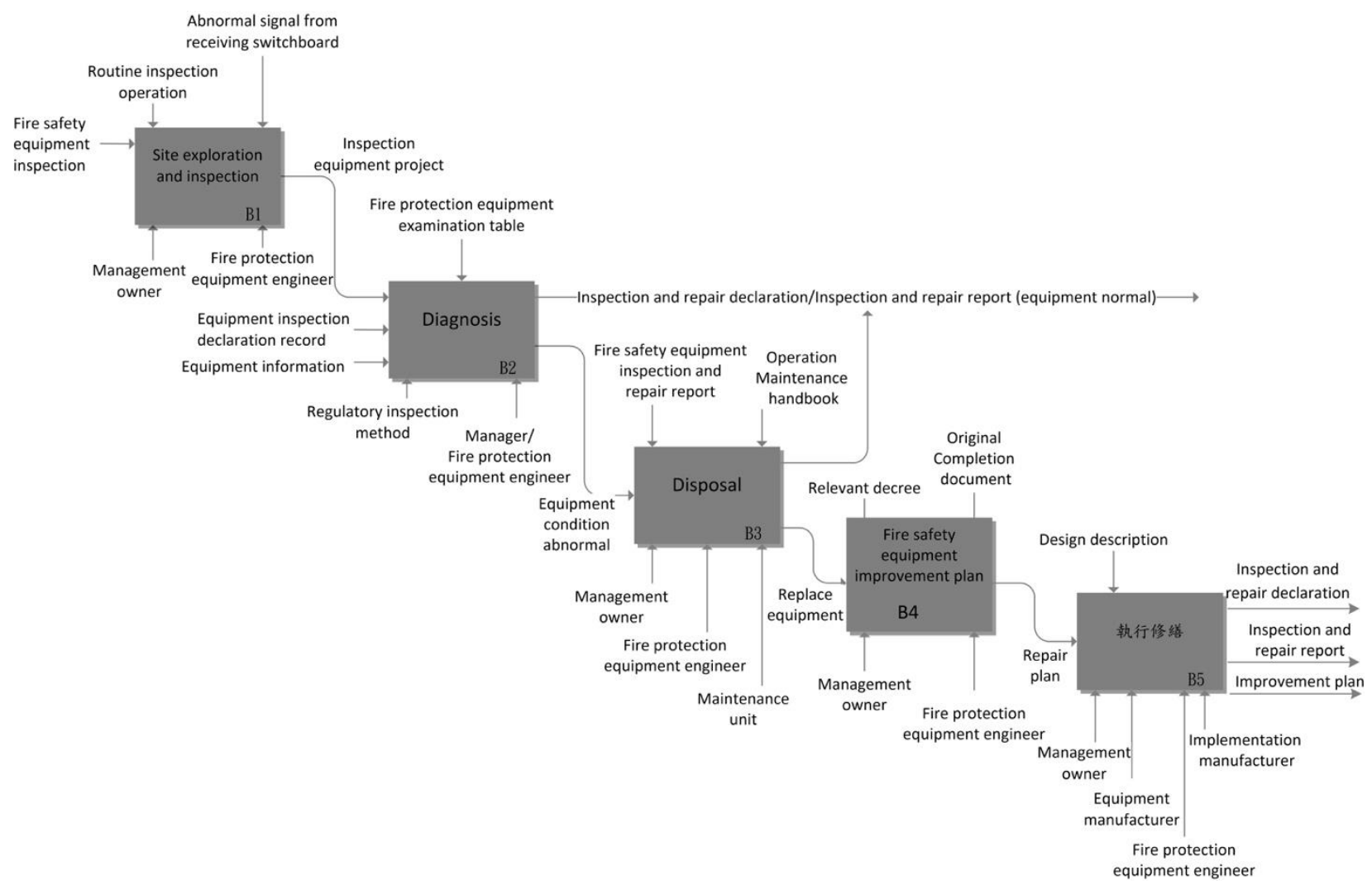

Fig. 3. Fire safety equipment inspection analysis process.

\section{Construction of BIM identification tracing and verification mode}

After the owner accomplishes information delivery standard, architects, contractors, and related units involved in the project develop a practical BIM model file according to the standards. After designing the file drawing, the owner must confirm whether each component is drawn according to the practical conditions and constructs the information content similar to the units involved in the construction based on the COBie organization requirement, to confirm the completeness and effectiveness of the whole project information delivery task.

This research uses Autodesk Revit 2016 as the modeling platform, constructs and links the COBie organizational information to the model via the COBie Toolkit application, concludes the content information required by fire protection safety equipment component inspection by the file format transformation and form arrangement of the BIM project information content. This is to present the inspection and maintenance information by identification tracing. Subsequently, this research paper clarifies the modeling content and provides the complete and effective visual 
information for AR. The following figure displays the BIM component construction identification tracing and inspection process, during which the simulation information application of the inspection task is verified. If the information present is unable to provide the related information for the participants according to standards, it is defined as insufficient information and the information content of the BIM model should be inspected again as shown in Fig. 4.

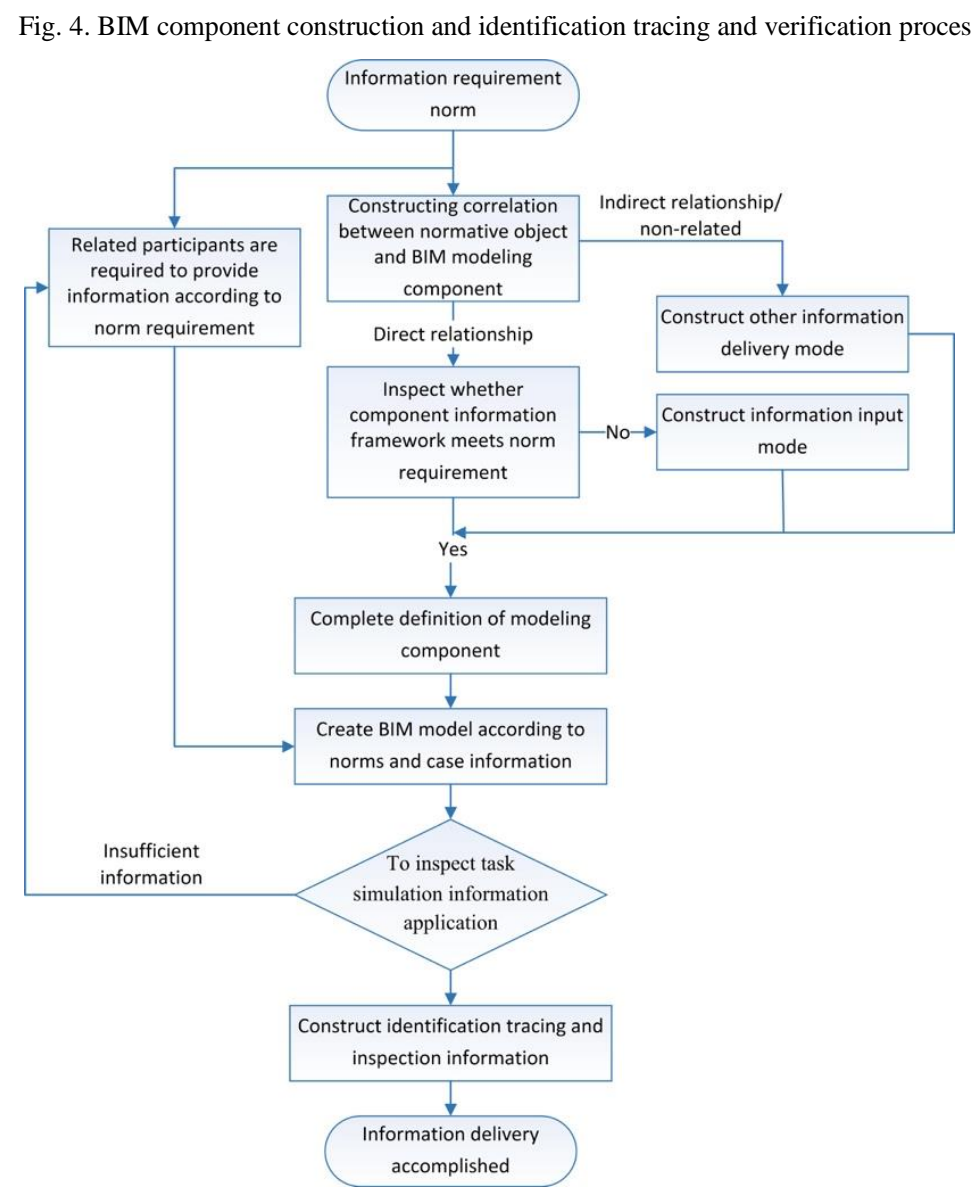

\section{System construction and case validation}

In this research study, the case validation system considers the administration building of a national university. During the process of the fire protection safety equipment inspection verification, first the regulations and inspection contents of the fire protection equipment should be known and then the information requirement of each component from the regulation inspection should be learned based on the defined component framework. Additionally, the information should be classified into the corresponding attribution of the liability and COBie organization structure via IDEF0 to generate the complete information delivery practice. Subsequently, the modeling staff is responsible for drawing the BIM case model according to the process and standards defined in this research. Then, the information required by the AR cloud end database is constructed and augmented by a format transformation, and the advantages and correctness of which is subsequently verified by practical cases. Consequently, the entire AR information delivery task is performed.

\subsection{Construction of augmented reality cloud end inspection system}

The construction of the AR cloud end inspection and maintenance system is completed based on the BIM model and COBie form. Prior to the system construction, the modeling staff should have a good knowledge of the cloud end database framework and be clear on the correlation of the construction of each database and the relevance of the construction. The framework of the cloud end inspection database designed in this research is shown in Fig. 5. The operating steps of this framework will be introduced subsequently. First, this system employs Revit 2016 as the BIM 
modeling platform and utilizes the Revit add-ins tool to export the COBie form and 3D model based on the model constructed by COBie Toolkit and OBJ Exporter to accomplish the AR framework. Furthermore, a mobile device application is used for the data construction. The data construction can be broadly divided into 3D model data and form (COBie form), file map, and file data. However, the 3D model data is the distribution of the inspection system pipeline for the inspection staff, and its corresponding application is called the Augment application, whereas the form (COBie form), file data, and file data application are the information of the inspection fire protection equipment for the inspection staff, and the corresponding application is FTPManager Free and Aurasma. Eventually, JotForm is adopted to construct a cloud end inspection feedback system, which feeds back the inspection result to the relevant maintenance staff and related unit in real time, stores the inspection result, and accomplishes the complete inspection and maintenance.

Fig. 5. The framework of the cloud end inspection database.

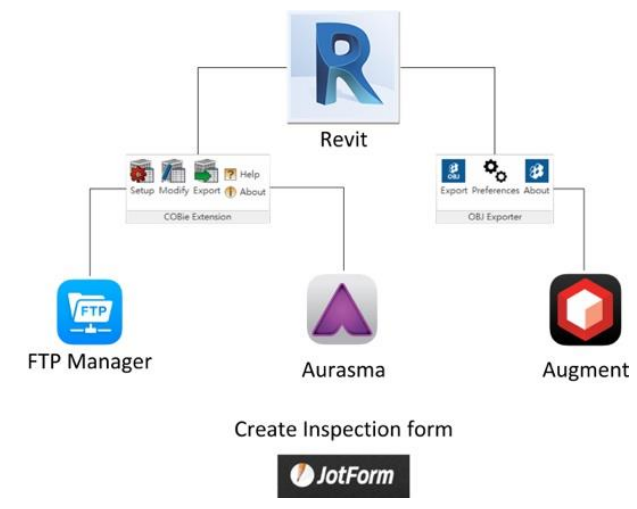

\subsection{Verification of augmented reality and cloud database delivered information}

In this research, following the accomplishment of the system, the relevant units (owners, maintainers, detectors, and fire device personnel) should confirm the information completeness and correctness by a case simulation. If any information error or omission is found, it is necessary for the relevant units in the project to correct it according to the specification requirements.

Because the COBie structure used is relatively complete, this research attempts to upload the COBie forms to the NAS cloud database and open Excel with the action device to directly extract the information required by each operation to realize immediacy, visibility, and convenience in information presentation.

In this study, the NAS folder applies the sheet name of the document in the Excel COBie forms for data establishment, and so herein, the folder is divide into system, type, and component. Thus, when the subsequent maintenance related units accept the detection results, it is feasible to open the Excel COBie forms using NAS to search for the corresponding files in in files of the document and examine the files and graphics.

In this research, system simulation is conducted based on the alarm signal from the receiver to test its real-time application. The function and effectiveness of the system information and operation introduction are discussed below.

(1) The fire alarm receiver sends the alarm signal: 1F-2 loop lamp at the north building is on.

(2) Allocate and detect the loop range:

A. Open the Augment application to scan the fire device detection entry (as shown in Fig. 6), and it is necessary to detect the loop range for reference.

B. Confirm the loop and components of the received images: confirm the fire source using the loop. If there is no fire source condition, open the application Aurasma, to scan the fire device detection entry corresponding to each component in the loop for the detection operation, as shown in Fig. 7.

(3) Failure detection diagnosis

A. Identify the fault component: fire alarm panel (manual alarm): log in FTPManager Free to refer to the regulation detection information.

B. Detect the results and causes: the manual alarm causes a button to short-circuit owing to dampness. Open the JotForm network detection forms to send the detection results to the maintenance-related units.

(4) Maintenance and repair operation

A. Maintenance-related units provide e-mail information: after confirming to have sent the name/unit of the 
detector, $\log$ in to FTPManager Free to examine the type of faulty component and open the Excel COBie forms to refer to the component type (Fig. 8).

B. Examine the product catalog: log in FTPManager Free: fire detection and maintenance system, type, fire alarm panel, catalog, fire alarm panel (wall-mounting type) (Fig. 9).

C. Change parts: when the maintenance unit checks the catalog, bring the relevant parts to the designated space only (when establishing the research component, it should be named after the space) for repair.

By the above simulation operation, it is feasible to examine and detect if the information content required by the maintenance operation is sufficient or complete. If there is any omission, the data builders can conduct data expansion based on the condition requirements to satisfy the convenience and completeness required by the detection and maintenance operation.
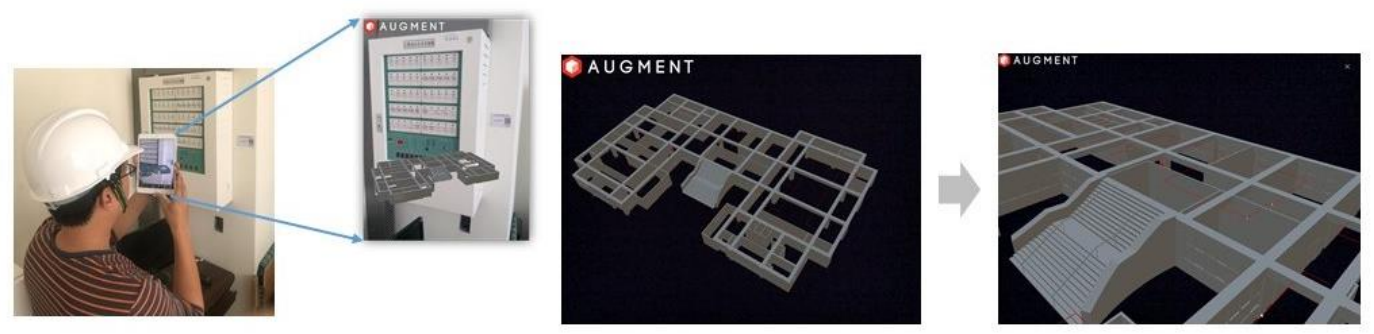

Fig. 6. Scan the fire device detection entry and detect the loop range for reference.
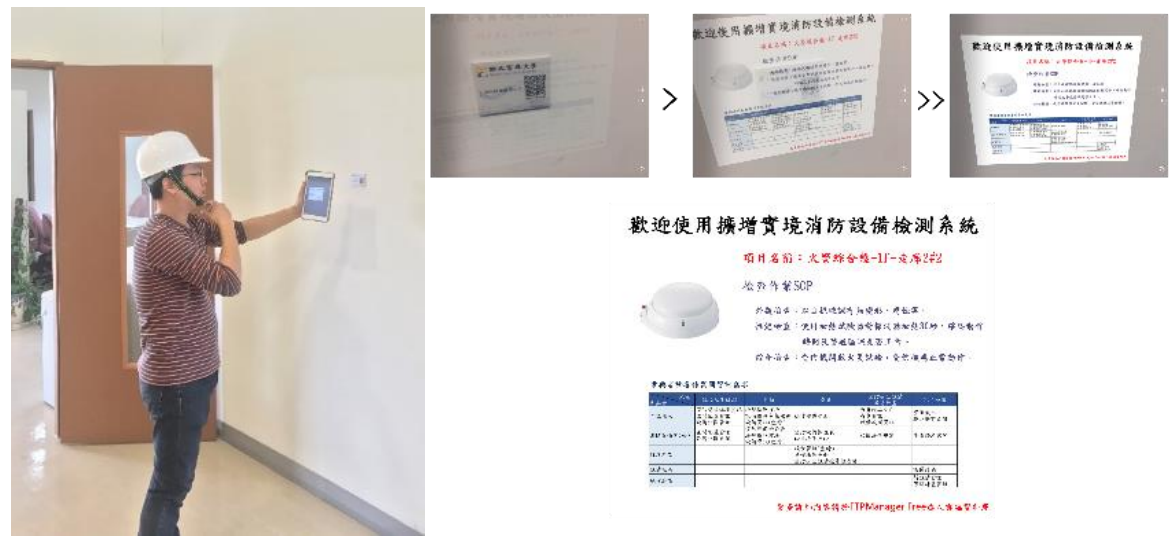

Fig. 7. Confirm the loop and components of the received images.

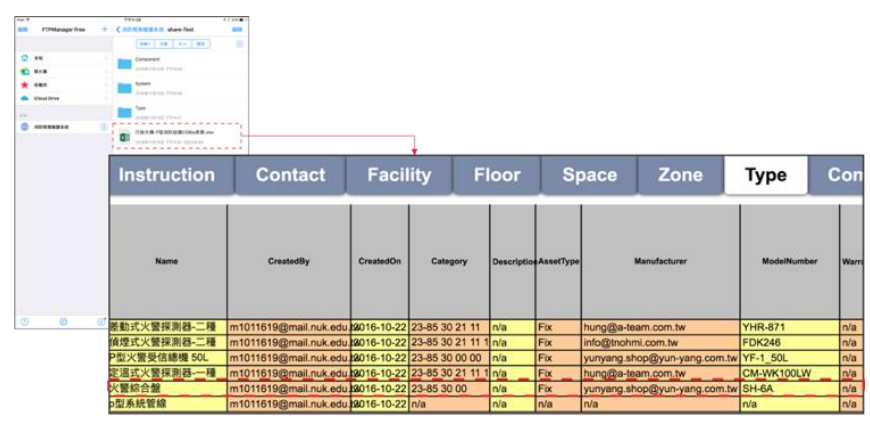

Fig. 8. Examine the type of faulty component in Excel COBie forms.

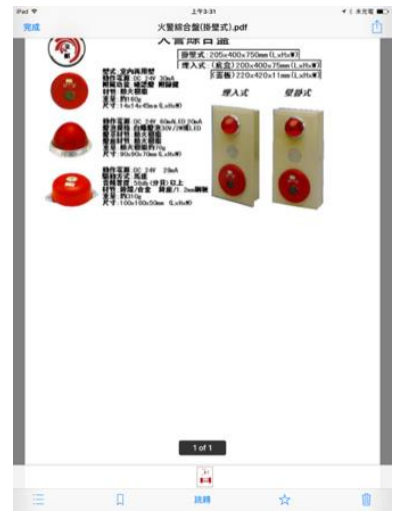

Fig. 9. Examine the product catalog. 


\section{Conclusions}

In this research, with the aim of detection and maintenance of the information by fire safety devices, the establishment of a BIM information model is attempted. Concurrently, based on COBie, expert interviews, information demands analyzed by IDEF0 and the information source in the project life cycle, the information should be organized by COBie to identify the complete delivery specifications that should be applied to establish the cloud database with the APP and NAS cloud memory servers of the organization. The online detection forms are established using JotForm to replace the traditional drawing records and realize real-time feedback to eventually form a detection and repair system consisting of fire safety devices that combine BIM and AR. Then, the feasibility tests of the system functions are conducted on actual cases and the testing results exhibit the effectively provided immediacy, visibility, and convenience of the data presentation of the fire detection and maintenance operation. The detection information system established in this research can assist detectors, fire device personnel, and maintenance units for effectively conducting the maintenance and detection operation in real time and solve the inconvenience caused by the requirement of drawing information. Thus, the system mode established in this research can satisfy the objective of this research. In addition, it can also be found from the analysis process of this research that though the research framework can analyze the information requirements and application modes, it remains difficult to analyze the specific information requirements owing to the lack of detection experience of the analyzers. Therefore, expert experience can exert a significant effect on the analysis process of this research.

\section{Acknowledgements}

This work was supported by the Ministry of Science and Technology, Taiwan under Grant MOST 106-2221-E-390005 .

\section{References}

[1]. East, E. W., Nisbet, N., \& Liebich, T. (2013). Facility management handover model view. Journal of Computing in Civil Engineering, 27(1),61-67.

[2]. Fallon, K.K., \&Palmer, M.E. (2007). General buildings information handover guide(NIST Interagency/Internal Report (NISTIR) -7417). Maryland: NIST.

[3]. Tserng, H. P., Yin, Y.L., Jaselskis, E., Hung, W. C., \&Lin, Y. C. (2011). Modularization and assembly algorithm for efficient MEP construction. Automation in Construction, 20(7), 837-863.

[4]. Zhang, X.Q., \&Gao, H. (2010). Optimal performance-based building facility management. Computer-Aided Civil and Infrastructure Engineering, 25 (4), 269-284

[5]. Eastman, C., Teicholz, P., Sacks, R., \& Liston, K. (2011). BIM handbook: a guide to building information modeling for owners, managers, designers, engineers and contractors, Second Edition. New Jersey: Wiley.

[6]. Lin, Y. C.,\&Su, Y. C., (2013). Developing mobile-and BIM-based integrated visual facility maintenance management system. The Scientific World Journal, 2013.

[7]. Wang, Y., Wang, X., Wang, J., Yung, P., \&Jun, G. (2013). Engagement of facilities management in design stage through BIM: framework and a case study. Advances in Civil Engineering, 2013.

[8]. Hou, L., Wang, X., Bernold, L.,\&Love, P.E.D. (2013). Using animated augmented reality to cognitively guide assembly. Journal of Computing in Civil Engineering, 27 (5), 439-451.

[9]. Meža, S., Turk, Z., \& Dolenc, M. (2014). Component based engineering of a mobile bim-based augmented reality system. Automation in Construction, 42, 1-12.

[10]. Chu, M., Matthews, J., Love, P.E.D., (2018). Integrating mobile Building Information Modelling and Augmented Reality systems: An experimental study. Automation in Construction, 85, 305-316.

[11]. National Institute of Standards and Technology (NIST) (2006).Capital facilities information handover guide, Part1.U.S.National Institute of Standards and Technology. 